\title{
Editorial
}

\section{Teaching Professional Ethics}

Ethics, as a topic of investigation, discussion, and debate, must be fully integrated into our professional school curricula. Educators must play a central role in guiding the ethical development of information professionals.

In most occupational fields, a basic assumption is that high standards of personal integrity, responsibility, reliability, accountability, honesty, and competency should govern all actions and decisions of those who call themselves professionals. Indeed, the extent to which these standards are articulated, taught, enforced, and sanctioned in a field is a gauge of the degree to which the public views that field as a true profession. The centrality of ethics to a profession becomes obvious when an ethical error ends a career, which happens just as often, and is a greater tragedy, than a career ending because of a lack of knowledge, poor business judgment, or other professional mistake.

Ethics are linked to values. What are the values of the field of library and information services? Are they rooted in economic advantage or equality of economic opportunity, in personal self-fulfillment or societal benefit, in cultural solidarity or cultural diversity?

Every profession must address questions of ethics and values, and must examine the underlying assumptions of ethical standards and value systems, to determine whether they hold up for a pluralistic society and a shrinking world. Each profession, moreover, must interpret general ethical standards into specific work situations. Certain time-honored religious value systems, that have been encoded and preserved in the Torah, the Koran, the New Testament, and other religious books, have been guides to eternally valid principles. They do not address, however, the nitty-gritty everyday ethical dilemmas that professionals face.

Ethical issues arise daily, as information professionals interact with each other (especially in personnel actions), with clients and users, and with society in general. Ethical considerations also govern individuals' choices for themselves- - in instances of self-interest that conflicts with the interests of others, and in off-duty behavior.

A multiplicity of situations in the information field thus have consequential ethical dimensions. A few examples:

1. Confidentiality is a crucial ethical issue, and can be breached easily in library 
settings: in reference work, online searches, circulation systems, and online catalogs. Librarians must take great care to protect confidentiality, to bar those who would rummage in information use records (such as the recent probe by the U. S. Federal Bureau of Investigation). The practical issue is often one of proper storage and destruction of records that could contain confidential information, but the ethical issue involves the courage to resist well-intentioned, but dangerous, breaches of confidentiality.

2. The highest standards of reference service demand helping all requestors to find full and accurate answers to questions. But suppose the question is: "What are some ways to poison a city's water supply?" Or, "How can an individual bypass airport security in order to commit a terrorist act?" A librarian may never receive questions so blatantly criminal, dangerous, or inhuman, but may hear questions that are suspect in some way. Or some clients may appear to too inexperienced, immature, ignorant, or reckless to use certain information in a responsible way. Should a librarian refuse to answer some questions? Ethics are not just about what is universally right and wrong, but are concerned also with exercising judgment of right and wrong in particular circumstances. A further complication is that situation-specific ethical judgments can appear to others as unfair or contradictory. Ethics require accountability for one's actions. This field will not be taken seriously as a profession if librarians passively refuse to make difficult judgments and to assume responsibility for the consequences of their professional practices and decisions.

3. Organizations expect information searchers and analysts to support institutional research goals. How should professionals respond, however, when asked to gather information for projects that have aspects that violate their feelings on sensitive issues, such as animal rights, chemical weapons, capital punishment, or substance abuse, or that will intrude on someone's privacy? Should professionals be valueneutral toward information they handle? Can they be? The American Library Association (ALA) Code of Ethics states that "librarians must distinguish clearly in their actions and statements between their personal philosophies and those of an institution." However, this statement does not resolve the problem. Neutrality is impossible; ethical tension is always created whenever professional judgments impact personal biases that represent deep convictions and basic values. The neutrality issue affects not only searchers and analysts, but everyone involved in the selection, acquisition, storage, organization, and dissemination of information.

4. The ALA Code of Ethics holds that "librarians must resist all efforts by groups of individuals to censor library materials." Resisting censorship pressures in specific cases, however, may have to be balanced against other values of the individual and of the community.

5. Free and equal access for everyone to unlimited information resources is a splendid, but unrealistic, ideal of this profession. Economic constraints require professionals to think in ethical terms in order to determine fair access to expensive, limited information resources. Resolving access issues ethically is especially critical when the 
information lies in an area seen as part of the common good-such as agriculture, education, or health.

6. Information professionals who must interact with vendors of library materials or automated systems may view out-of-office socializing on vendors' expense accounts as a way to facilitate negotiation of delicate economic and service issues. At what point does such quasi-social business interaction involve an unethical conflict of interest?

7. As more automated information products are designed for direct end user access, searching specialists are noticing that some users lack the skills and knowledge to search effectively. Even when users are blissfully unaware of their own deficiencies and even resent the intrusions of a professional, it may be unethical for librarians to leave them to their own devices, to not provide guidance to help them achieve adequate and appropriate results.

Information technology raises other general ethical issues. New computer-based systems that allow more rapid and thorough retrieval of information have brought with them the promise of a general improvement in the quality of human life. The information in medical databases will eradicate some diseases. Agricultural information will reduce world hunger. Environmental information will lower pollution. And so on. These information technologies, however, also have increased the potential for abuse and misuse of information. Only by addressing the ethical issues involved can information professionals ensure that the wealth of information retrieved will be used wisely for the benefit of all mankind.

A profession's stance on ethical issues can be drawn in a code of ethics. A code, however, that has not adapted to contemporary and diverse situations, however, cannot resolve all issues that arise. As an illustration, the Hippocratic Oath, the most ancient professional code, has not prevented a calamitous and increasing number of malpractice suits in the U. S. A code of ethics also raises issues of policing and sanctioning of violations that each profession must resolve as appropriate. Nonetheless, a code of professional ethics is an inspiration to members of the profession, and allows them to communicate what they stand for to the outside world. It is a major component of quality assurance for the field. At the least, a code can be a platform for increased awareness and reflection on ethical and values issues.

No code, however, can solve all the ethical problems of a profession unless a solid foundation in ethics and values has been bred from the beginning into every member of the profession. Professional school education thus must play an important, even a central, role in ethics for the profession.

Schools that abdicate the teaching of ethics and values leave the job to practitioners, some of whom will not be good teachers. While some practitioners can and will provide admirable models of handling difficult situations, they cannot be counted on to do so invariably. Young professionals must have their own internalized ethical standards. The best place to nurture these standards is in school, as an integral part of teaching knowledge and skills. Working professionals can find themselves in situa- 
tions with conflicting ethical responsibilities and competing demands from administrators, staff, users, and society. Practice in resolving perplexing ethical dilemmas in school is a good way to prepare for the demands of professional work.

Another benefit of faculty and students exploring ethical issues together is that relationships of trust can be built that graduates can use later. Those who know that they can call on their professors again for a non-judgmental discussion, are less likely to feel overwhelmed and dispirited by an unresolved ethical dilemma. The lack of a clear idea of how to cope with ethical predicaments can contribute to "burnout" and the premature withdrawal of a professional from the field.ô Ethics education is thus a form of career insurance.

In many schools, ethics and ethics codes are covered as a unit in a basic introductory survey course or, occasionally, as a separate elective course. Ethics education, however, must permeate the curriculum. Given the broad range of ethical issues that professionals face, every subject-information technology, management, collection development, organization of information, or reference service, raises issues of ethical practice.

How are ethics and values best taught? The choices include analysis and discussion of case studies, individual paper writing projects, classroom debates, and more. Educators who have experimented with innovative and exciting teaching techniques should share their experiences with the profession through the published literature. Education for Information would be pleased to receive descriptive and analytical papers on the subject.

Trudi Bellardo 